\title{
Investigation of the Modulation of the Tidal Stream Resource by Ocean Currents through a Complex Tidal Channel
}

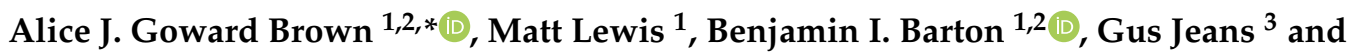 \\ Steven A. Spall ${ }^{2}$ \\ 1 Centre for Applied Marine Sciences, Bangor University, Menai Bridge, Isle of Anglesey, Bangor LL59 5AB, \\ UK; m.j.lewis@bangor.ac.uk (M.L.); b.barton@bangor.ac.uk (B.I.B.) \\ 2 Knowtra Ltd., Llandudno, Conwy LL30 2RD, UK; steve.spall@knowtra.com \\ 3 Oceanalysis Ltd., Wallingford OX10 0DD, UK; gus.jeans@oceanalysis.com \\ * Correspondence: a.j.gowardbrown@bangor.ac.uk
}

Received: 9 September 2019; Accepted: 25 September 2019; Published: 28 September 2019

\begin{abstract}
Tidal energy has the opportunity to bring reliable electricity to remote regions in the world. A resource assessment, including the response of the tidal stream resource to fluctuations in the Indonesian Through Flow (ITF) is performed using the Regional Ocean Modelling System (ROMS) to simulate four different scenarios for flow through the Lombok Strait in Indonesia. Tidal currents simulated with a variable ITF are compared against a tide-only (TO) simulation to identify how the ITF spatially changes the resource across the Lombok Strait. We find that the uncertainty in the tidal currents from the TO simulation is $50 \%$ greater than the variable ITF simulation. To identify change to resource, surface velocities from Strong ITF and Weak ITF scenarios are considered. As a result of the fluctuations in the ITF, certain characteristics, such as the asymmetry and magnitude, of the tidal current vary greatly. However, the magnitude of change is variable, with regions to the west of the strait experiencing greater modulation than in the east, suggesting that resource uncertainty can be minimised with selective site positioning.
\end{abstract}

Keywords: tidal energy; Indonesian Through Flow; tidal resource; hydrodynamics; ocean modelling; Indonesia; ocean currents; ROMS

\section{Introduction}

\subsection{Indonesia's Energy Demand}

As the tidal-stream industry progresses, tidal stream developers are looking to export their proven technology to the global market. Island nations, such as Indonesia, have great potential for tidal stream development. Indonesia is one of the 185 parties to ratify the Paris Agreement and has to voluntarily reduce $29 \%$ of greenhouse gas (GHG) emissions (against their 'business as usual' levels) by 2030 [1].

Cost is a driver of renewable energy development, in the case of Indonesia, domestic supplies of fossil fuels have dwindled and, Indonesia has become a net importer of oil and gas [2]. In 2013, the amount of electricity produced was less than the total energy demand, which is set to increase exponentially-in what could be termed a doubling sequence, from 52 GW in 2013 to 115 GW by 2020 and $430 \mathrm{GW}$ in 2050 [3]. To help tackle this deficit, the Indonesian government have committed to increase the contribution of renewable technologies to $17 \%$ of the energy mix by 2050 [4].

In archipelagic nations, the demography and electrification ratio are important factors to be taken into account, alongside available tidal resource, when selecting appropriate tidal stream 
technologies. The development of renewable energy schemes (both micro community-based, and large-scale commercial developments) will improve quality of life in many cases, reduce fuel poverty and domestic demand for fossil fuels, as well as contribute to global emission targets. Indonesia has the 4th largest population in the world (264 million as of 2017) [5] and the consumption of electricity in Indonesia is dominated by its households. Up to $88 \%$ of Indonesia is electrified, leaving up to 35 million people without access to electricity [3]. Micro-hydro and micro-solar technologies are one utilisation strategy for government plans of near-universal access by 2020 .

\subsection{Indonesia's Tides}

Its geographic complexity, the result of the archipelagic nature of the region, consequently leads to tidal currents which have high levels of asymmetry and misalignment. In addition, the Lombok Strait, is the second most important strait in Indonesia for the transport of warm, less saline, water between the Pacific and Indian Oceans (see Figures 1 and 2). The tidal transport through the Lombok strait is strongly modified by non-tidal flow (typically from north to south), in the form of the Indonesian Through Flow (ITF), an ocean current of global significance (akin to the Gulf Stream in the Atlantic). The ITF is driven by a pressure gradient between the Pacific and Indian Ocean and is predominately generated by the monsoon [6]. Regions where non-tidal currents are shown to be frequently present is displayed by Figure 1.

The combination of strong tidal flows interacting with the sill between the islands Nusa Penida and Lombok, and stratification generated by the different thermohaline properties of the Pacific and Indian Oceans, leads to the creation of non-linear internal solitary waves [7]. These internal waves can be identified by satellite imagery, Figure 3 [7], and propagate both northward and southward through the Lombok Strait reaching speeds of up to $2.5 \mathrm{~m} / \mathrm{s}$ [8].

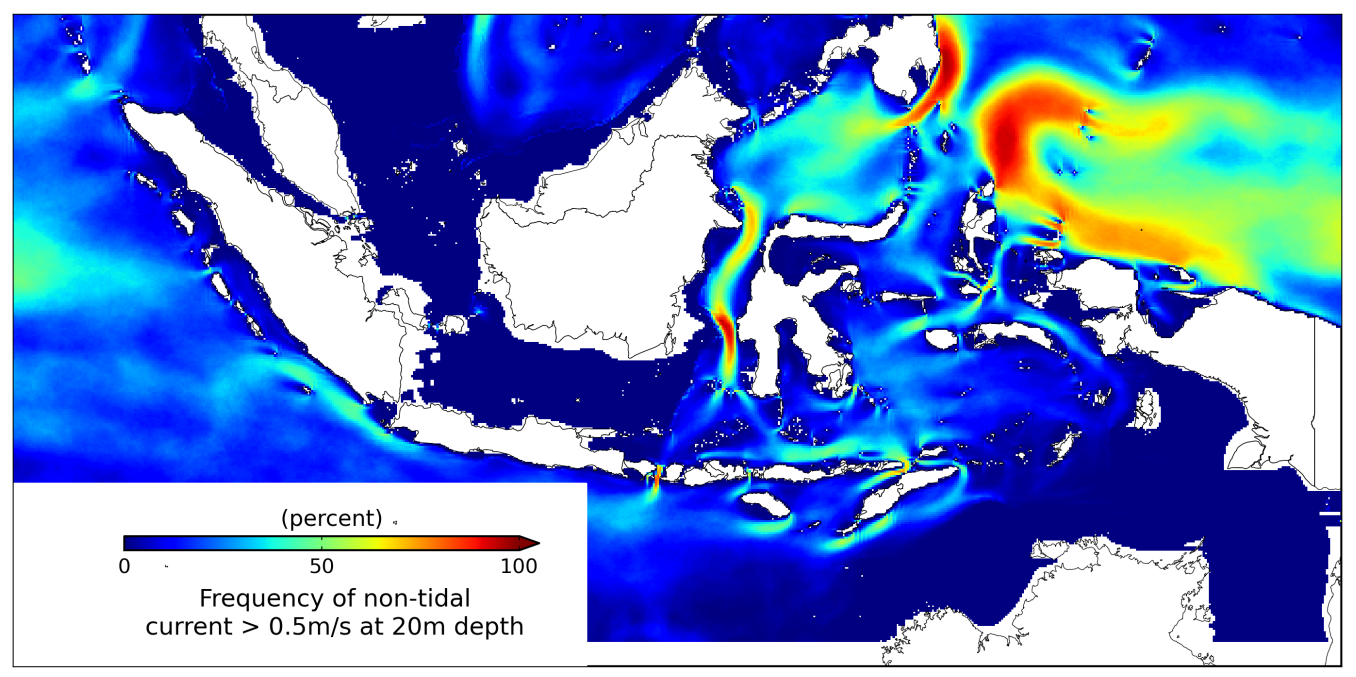

Figure 1. The frequency of non-tidal currents exceeding $0.5 \mathrm{~m} / \mathrm{s}$ at $20 \mathrm{~m} \mathrm{depth}$, diagnosed from the HYCOM global hydrodynamic model. Note the Lombok Strait (see Figure 2) has persistent non-tidal currents. 


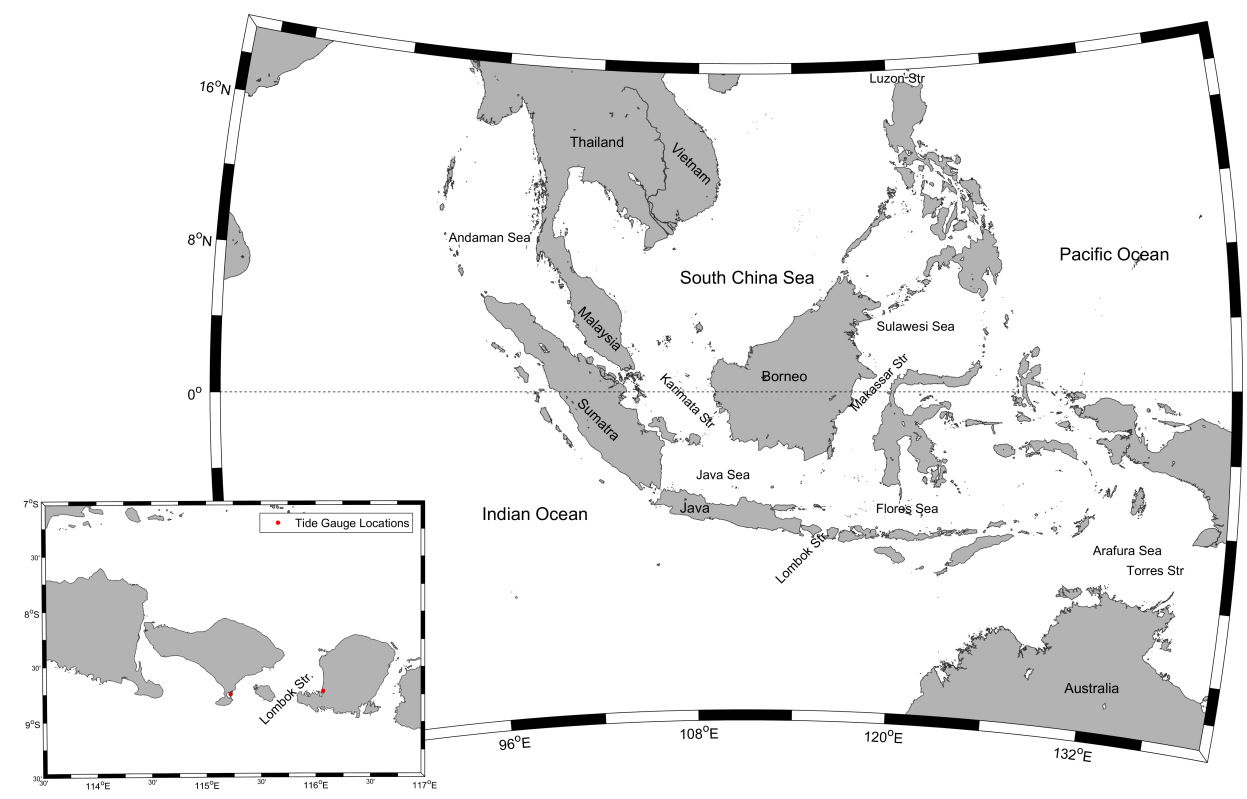

Figure 2. Map showing Indonesia with ROMS model domain inset. Tide gauge locations indicated by the red dots in the inset figure.

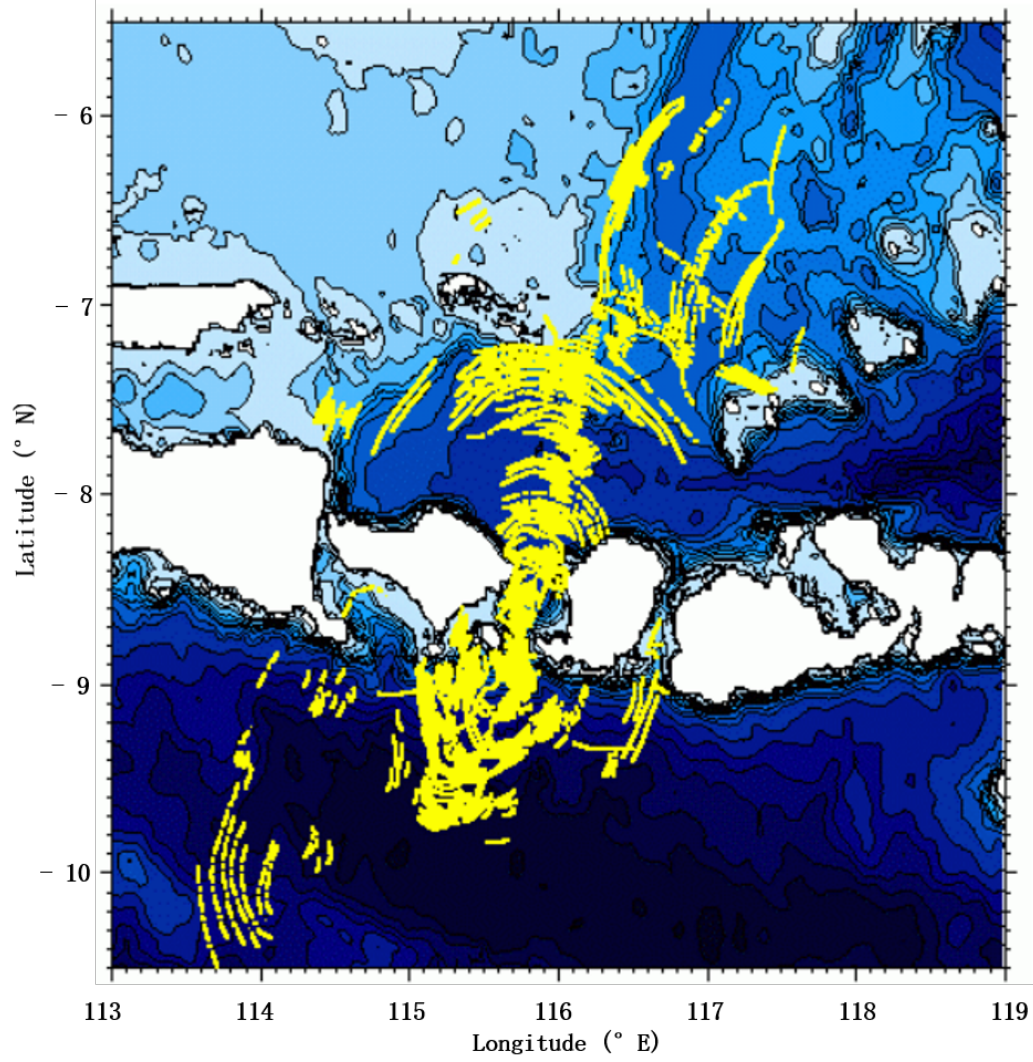

Figure 3. Composite map showing internal wave crests from all available images covering the Bali Sea region. From [7].

All of these complex oceanographic processes are interlinked. The quantification of the variability of the ITF is a research problem in itself, and much research effort has been exerted on this subject 
(e.g., [9-11]). However, relatively few studies on tidal resource have been carried out for this region, a factor in this could be the lack of reliable data for model attribution and validation.

In order to identify the nature of the tides in a region, the Form ratio $(\mathrm{F})$, the ratio between the diurnal tidal constituents and the semi-diurnal constituents, can be used (Equation (1); [12]). If F is less than 0.25 then the tides are said to be semi-diurnal ( 2 high and 2 low tides a day) and the two main diurnal constituents have little impact on the overall tidal wave. An F value between 0.25 and 1.5 gives a mixed tide, but with a strong semi-diurnal influence. Values between 1.5 and 3.0 are also mixed tides but are strongly influenced by the diurnal constituents. Above 3.0 the tides are classed as diurnal (one high and one low tide a day) as the semi-diurnal constituents are negligible.

$$
F=\frac{H_{K_{1}}+H_{O_{1}}}{H_{M_{2}}+H_{S_{2}}}
$$

where $H$ is the amplitude of the diurnal $\left(K_{1}\right.$ and $\left.O_{1}\right)$ and semi-diurnal $\left(M_{2}\right.$ and $\left.S_{2}\right)$ tidal constituents, see Section 2.

The tidal regime around Indonesia can be classified as a "mixed". To see how this varies either side of the Lombok Strait two tide gauge records have been compared (see Figures 2 and 4). Using Form ratio theory, the tidal regime observed by both the Benoa (Denpasar, Bali) and Lembar tide gauges (Pulau Lombok) can be identified as mixed, with less of a semi-diurnal influence at the Benoa gauge than at the Lembar gauge with respective form ratios of 0.41 and 1.27 after tidal analysis of the tide gauge data with $T_{-}$Tide [13].

This differs from the majority of tidal-stream resource research to date which have focused on regions dominated by semi-diurnal tides $\left(\mathrm{M}_{2}\right.$ and $\mathrm{S}_{2}$; i.e., $\left.[12,14,15]\right)$.

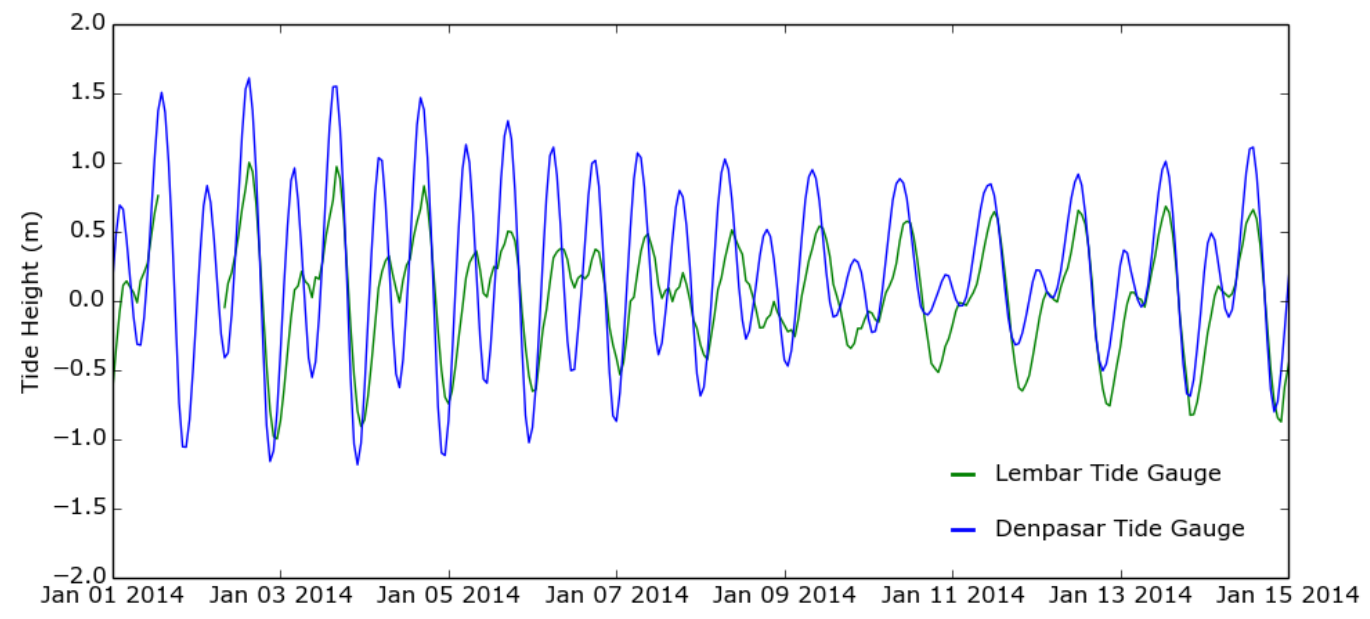

Figure 4. Comparison of tide gauge records.

\subsection{Indonesia's Tidal Energy Resource}

The aim of this hydrodynamic modelling work has been to better quantify the nature of the currents (tidal and non-tidal) for selected areas of Indonesian waters for tidal stream energy development. To model the currents through these Indonesian straits, the Regional Ocean Modelling System (ROMS) is used (http:/ / www.myroms.org/) with varying boundary inputs in an attempt to quantify the influence of the ITF. Initially, we compare the baroclinic ROMS model set up to global FES 2014 tidal model (https: / / www.aviso.altimetry.fr/en/data/products / auxiliary-products / global-tide-fes.html), available at a spatial resolution of $1 / 16^{\circ}$, interpolated to a common grid for the inter-model comparisons (in all cases the ROMS 450 m computational grid, described in Section 2, 
is used), to determine whether global altimetery products can be an alternative to computationally expensive, highly resolved 3-D models.

The difference between our model set-ups are therefore assumed to represent the sensitivity to the interaction of the ITF and the tide, and thus can be used to further interrogate how the ITF modulates the tidal resource-hypothesising that understanding the position of the ITF in the channel will be an important step for tidal resource planning in this region.

\section{Materials and Methods}

The 3-D ROMS model of Indonesia has a spatial resolution of approximately $450 \mathrm{~m}$. In technical terms, ROMS is a state of the art, free surface, terrain-following, finite difference primitive equation hydrodynamic model which undergoes constant development by its active user community [16]. Due to the complex nature of the tidal currents in Indonesia, a 3-D model was considered the most appropriate tool for the task of simulating the variation of tidal currents over the entirety of the water column. The model domain extends between $9.2^{\circ} \mathrm{S}, 117^{\circ} \mathrm{W}$ and $7.9^{\circ} \mathrm{S}, 115^{\circ} \mathrm{E}$ to incorporate both the Alas and Lombok straits (Figure 5). The model bathymetry was digitised from the relevant Admiralty chart. In addition to this, the bathymetry at the model boundaries was supplemented by data from the ETOPO1 data set [17] which ensures a smooth transition at the boundary for the specified HYCOM currents. The sparse and irregular depth data is interpolated onto the regular model grid using a natural neighbour scheme. Currents at the boundaries are specified to enable the model to downscale large scale flows to the detailed flow through the straits. In order to simulate tides, the Oregon State University Tidal Prediction Software (OTPS) is used [18]. Tidal harmonic constituents, from the OTPS North Australia sub-area model, for the five most important harmonics in this region $\left(\mathrm{M}_{2}, \mathrm{~S}_{2}, \mathrm{~K}_{1}, \mathrm{O}_{1}\right.$, $\mathrm{N}_{2}$ ) are used to specify the horizontal and vertical tide at the model boundary. Note that the OTPS model assimilates water level data measured from satellite and hence derives tidal currents consistent with the time evolving water levels - in order to generate realistic tidal heights and flows. In addition to specifying currents at the model boundaries, we also include the heating and cooling of the sea surface, from ECMWF hind cast meteorological forcing data [19]. The model configuration was used to simulate 60 days, covering multiple spring/neap tidal cycles.

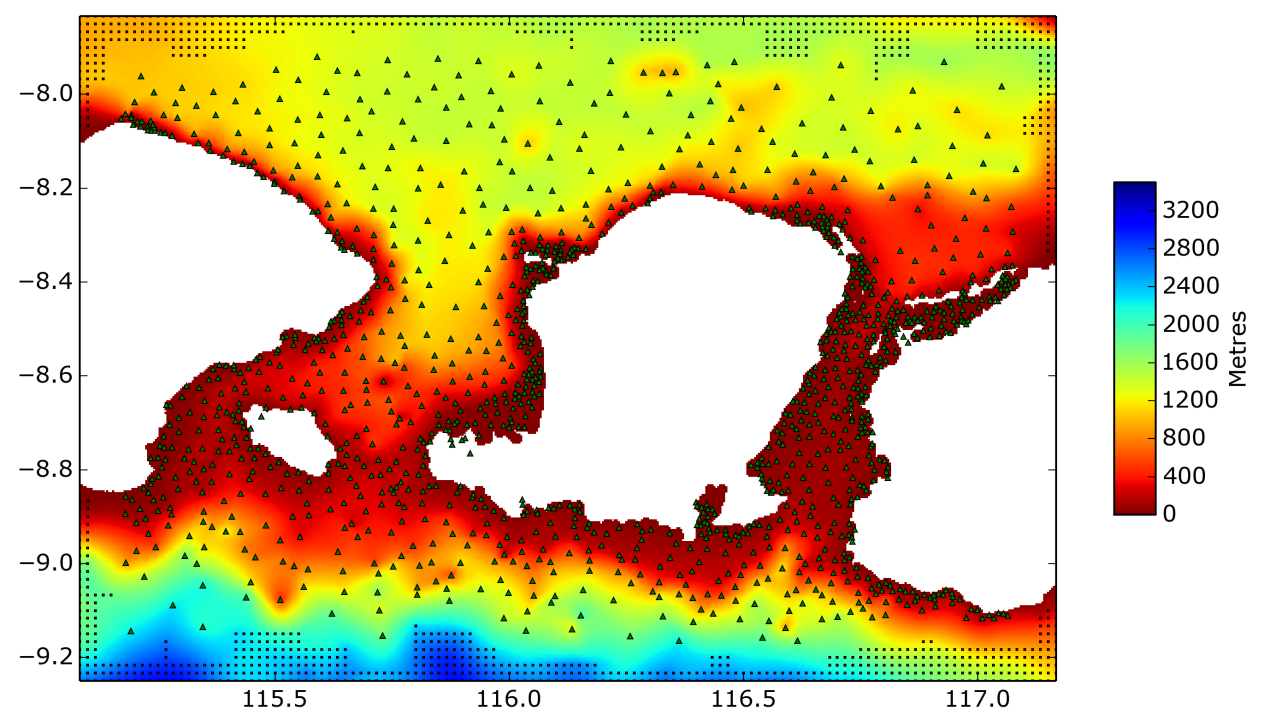

Figure 5. The model bathymetry over the model domain for the Lombok/Alas Straits model. The triangles are the locations of the Admiralty Chart data and the squares are the ETOPO1 data points used at the boundaries. 
In order to account for the Indonesian Through Flow (ITF), a global hydrodynamic model called HYCOM (https: / / hycom.org/) is used to specify non-tidal flows at the boundaries of the Lombok/Alas straits. HYCOM has been found to accurately simulate the passage of the ITF [20]. The ITF modifies the tides and provides additional flow, which we hypothesise will act to enhance the tidal energy resource when tidal transport is in the direction of the ITF and suppress the tide when it is in opposition to the ITF. The ITF varies in strength with time, and is hence much less predictable than gravitational tides. For this study, three cases are considered: a naturally varying ITF, a strong ITF and a weak ITF. These are illustrated in Figure 6.

The vertical structure of temperature and salinity properties is important to include in this region as drivers for non-tidal currents, these are also specified at the boundaries using HYCOM. On this note, the model was set up with 20 depth layers to ensure the thermocline was well resolved.
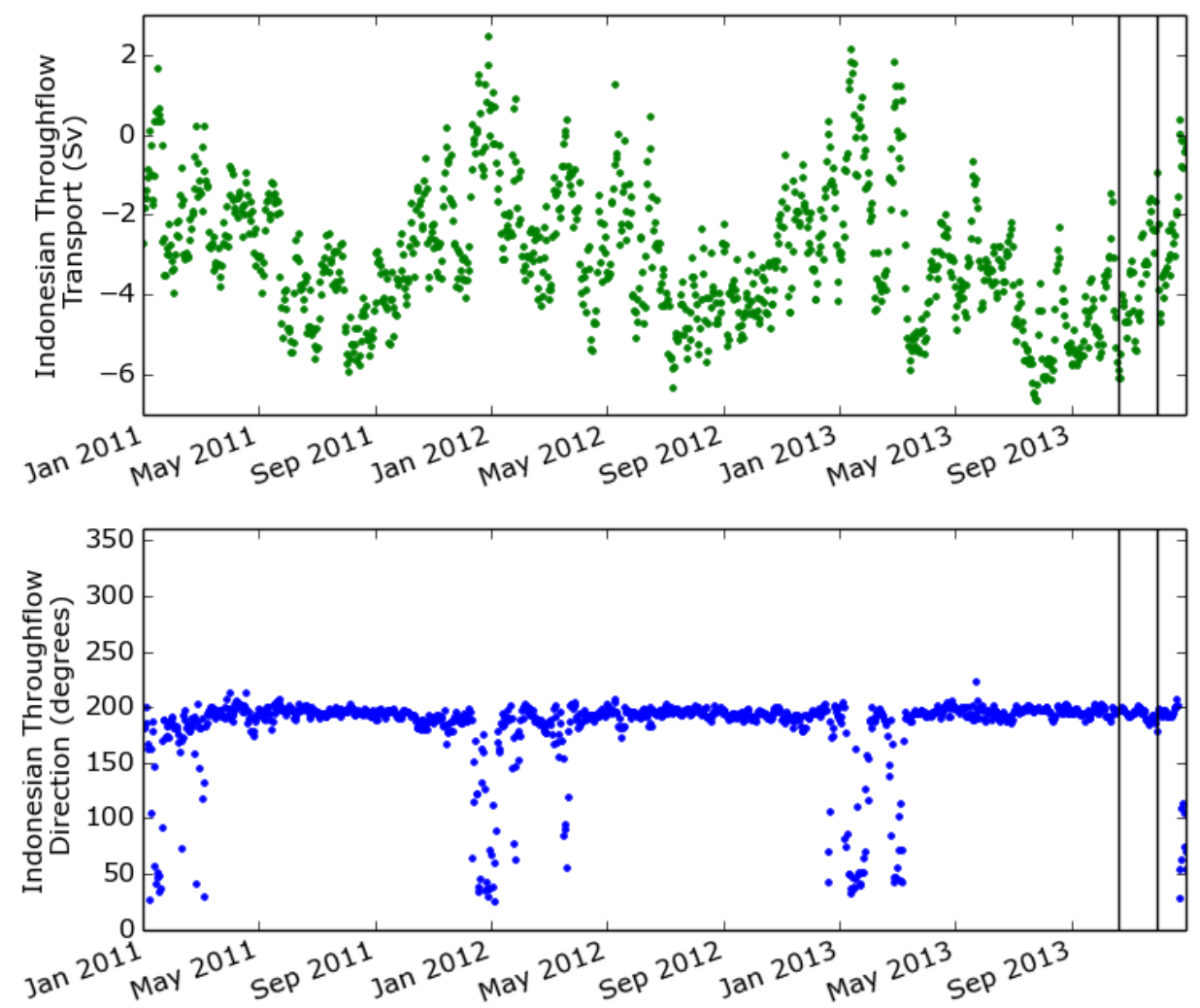

Figure 6. Time variation of the Indonesian Through flow in the Lombok Strait, as diagnosed from the HYCOM model. The vertical lines mark the times used to capture strong (first line) and weak (second line) ITF conditions. Flow units are Sverdrups (Sv) which is 106 cubic metres per second. Note, when Sv is negative it is flowing towards the south.

\section{Model Validation}

Ideally observational data would be available to validate the estimates of currents from the hydrodynamic model. However no such data has been available to the project, but the results from the models discussed here do show very similar currents to previous modelling studies (i.e., [21,22]) and to published maximum flow speeds based on observations.

For tidal elevation, there were two tide gauges located within the model domain. The Lembar tide gauge, situated on the east side of the Lombok Strait, and the Benoa gauge located south and west of Lembar on Bali (red dots, Figure 2). A comparison between the model and the data suggests a good fit and without velocity validation the matching of the phase suggests that we are capturing a good picture of current conditions (Figure 7). The root mean square error (RMSE) of the two tide gauges is $0.2 \mathrm{~m}$ and $0.3 \mathrm{~m}$ for the Lembar and Benoa gauges respectively (approximately less than $10 \%$ of the 
tidal range at these locations). Since elevation is accurate and phase is skillful, we assume the flux is correct and hence can have some degree of confidence in the simulations. It is worth noting, that since our results are predominately comparing how the tide reacts to varying conditions, it is the relative difference between the models which is of greater importance than the comparison to observed data, and hence we assume any error to be consistent.

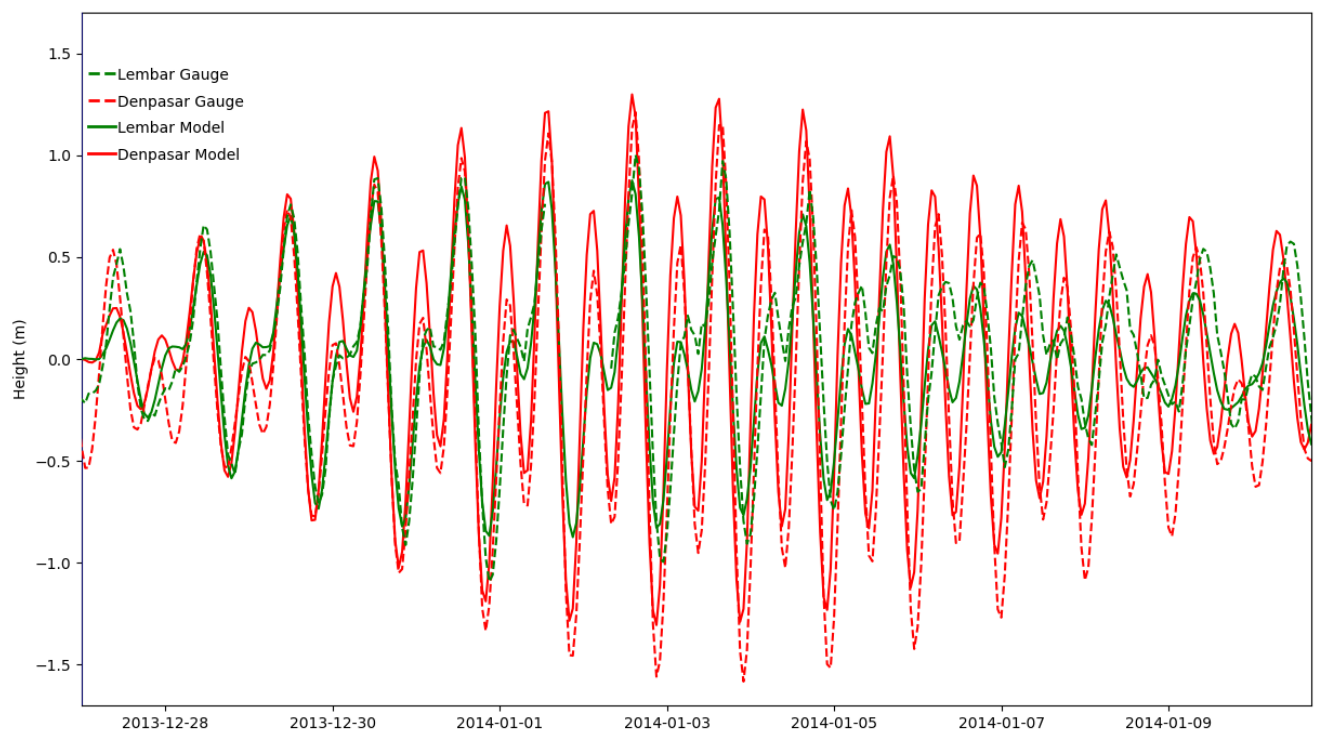

Figure 7. Comparison of modelled tidal elevation with available tide gauge records.

\section{Results}

A number of spatial and time series diagnostics have been derived from the hydrodynamic models, to inform and support the engineering analysis. Spatial maps of maximum flow speed, generated from the ROMS variable ITF model, show the persistence of strong flows and identify the Lombok Strait-where it narrows between the island of Penida and Lombok-as having the most potential for tidal stream energy extraction (Figure 8a).

To put this in the context of the tidal phasing, and to identify the most energetic areas, the percentage of time that velocities exceed the economically viable threshold of $1.5 \mathrm{~m} / \mathrm{s}$ has been plotted in Figure $8 \mathbf{b}$, which highlights the western side of the Lombok strait as being the most energetic with velocities exceeding $1.5 \mathrm{~m} / \mathrm{s}$ over $50 \%$ of the time.

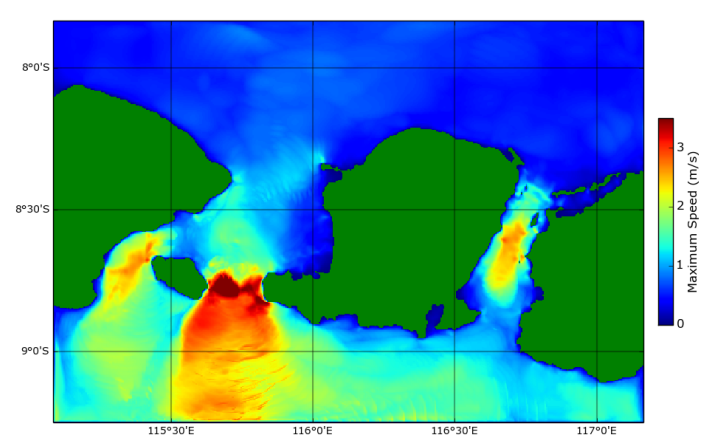

(a)

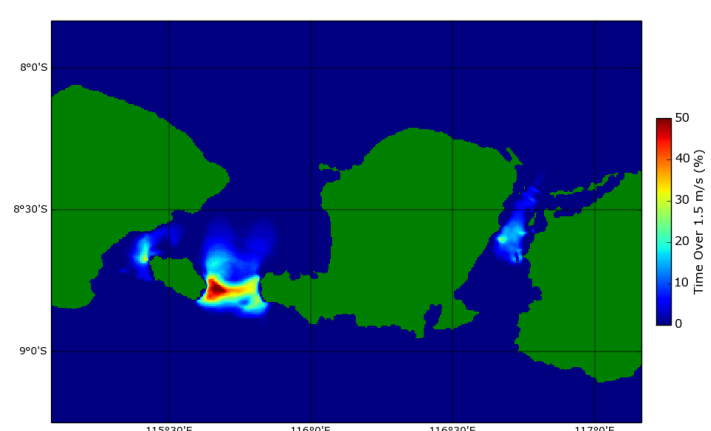

(b)

Figure 8. (a) The maximum surface flow speed; (b) \% of time velocities are greater than $1.5 \mathrm{~m} / \mathrm{s}$. 
How Does the ITF Influence the Lombok Strait Tidal Resource?

In order to assess how baroclinic effects influence the uncertainty in resource assessment in the Lombok strait region, the FES tidal data and the high resolution ROMS model are compared. FES is a finite element hydrodynamic model which derives tidal processes from an assimilation of altimeter and in situ data [23]. As for the ROMS set up (see Section 2), the same five main constituents were used to calculate the FES maximum current magnitude and Figure 9a,b show the FES model prior to, and after, interpolation to the ROMS grid resolution.

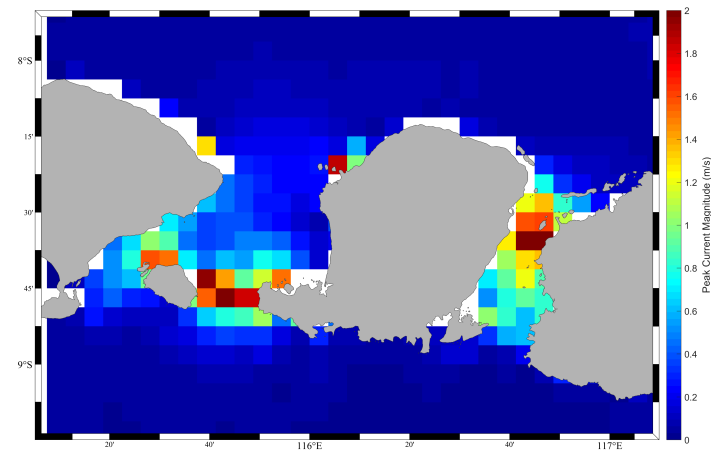

(a)

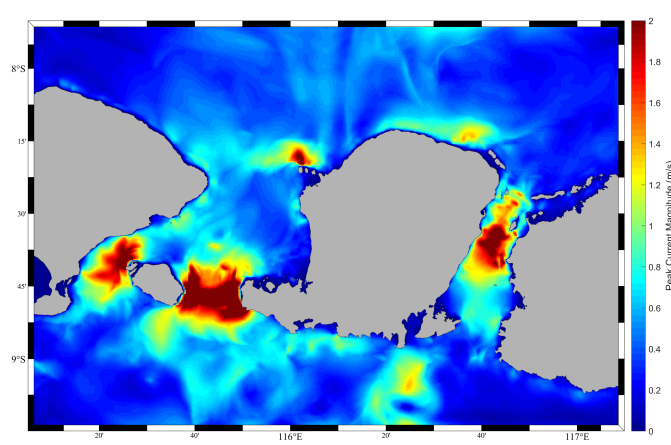

(c)

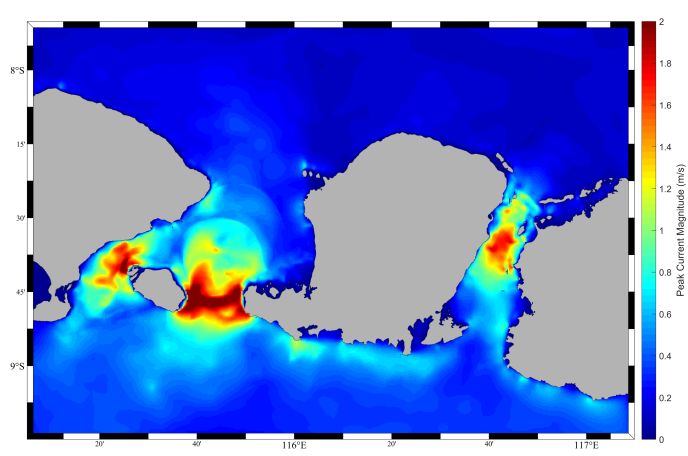

(e)

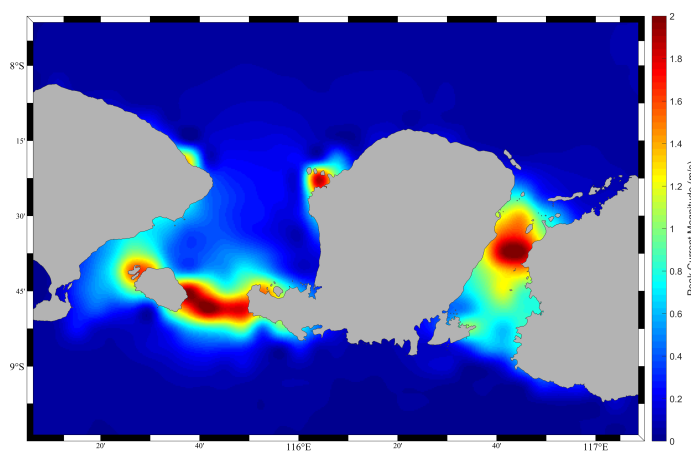

(b)

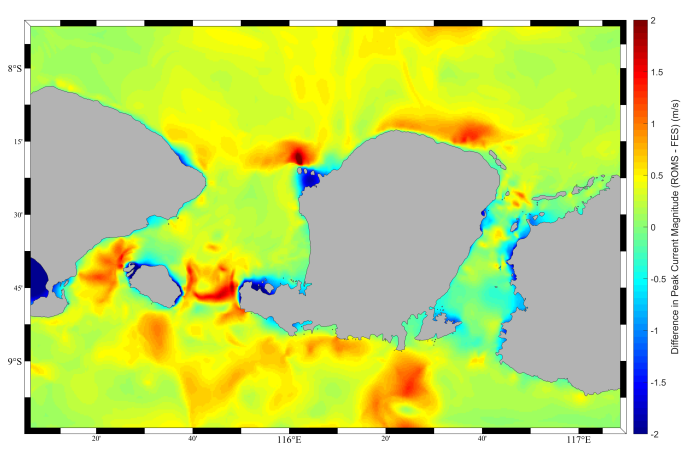

(d)

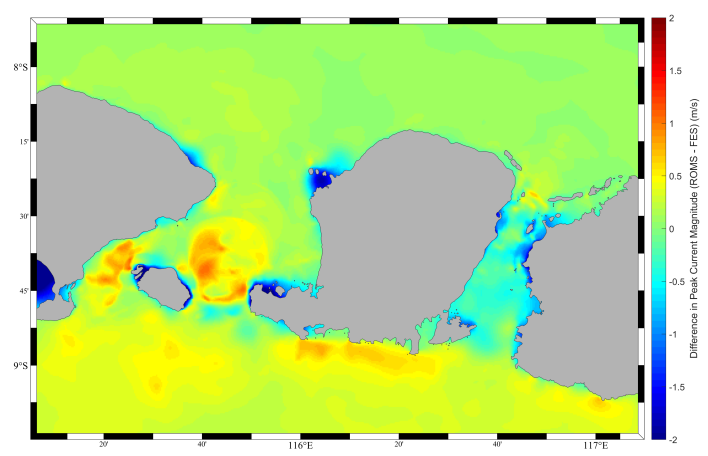

(f)

Figure 9. Spatial distribution of maximum current magnitude from (a) FES, (b) FES interpolated to the ROMS grid, (c) ROMS TO, (e) ROMS ITF. Figures (d,f) show the difference between interpolated FES data and the ROMS TO simulation (d) and the ROMS ITF simulation (f). 
Upon comparison with the ROMS peak current data, it can be observed that the FES model is able to roughly identify dynamic regions for resource extraction. Further investigation however, shows uncertainties in the peak magnitude exceeding $\pm 1 \mathrm{~m} / \mathrm{s}$ in the regions of interest for both the ROMS TO (Tide Only; Figure 9d) and ROMS ITF (ROMS with tides and variable ITF; Figure 9f) simulations. When compared against the ROMS ITF model, the FES data is more energetic with $72 \%$ more of the grid velocities exceeding the threshold of $1.5 \mathrm{~m} / \mathrm{s}$.

Looking between models, the difference in peak currents between the ROMS TO model and ROMS ITF model amounts to $2.3 \mathrm{~m} / \mathrm{s}$, less than the peak difference between FES and ROMS TO case which was equal to $2.7 \mathrm{~m} / \mathrm{s}$. The peak difference between FES and ROMS ITF is $1.1 \mathrm{~m} / \mathrm{s}$ which suggests that including the variation in the ITF is an important consideration for this region.

A comparison of the ROMS TO and the variable ROMS ITF models across the transect indicated by the red line in Figure 10, shows how the position of the tide varies with the ITF (Figure 11a,d). Figure 11a-c identify how the distribution of peak current magnitude, power density and temperature vary spatially across the channel for the ROMS TO simulation. Without the ITF the water column is well mixed (Figure 11c) and the peak tidal resource sits centrally in the channel (Figure 11a), as would be expected, due to the boundary effects of the channel sides. From Figure $11 \mathrm{~b}$ tidal streaming occurs between 50 and $75 \mathrm{~m}$ below the surface, where the bathymetry rises up at a longitude of $115^{\circ} 4^{\prime} \mathrm{E}$, resulting in the peak power density at this location.

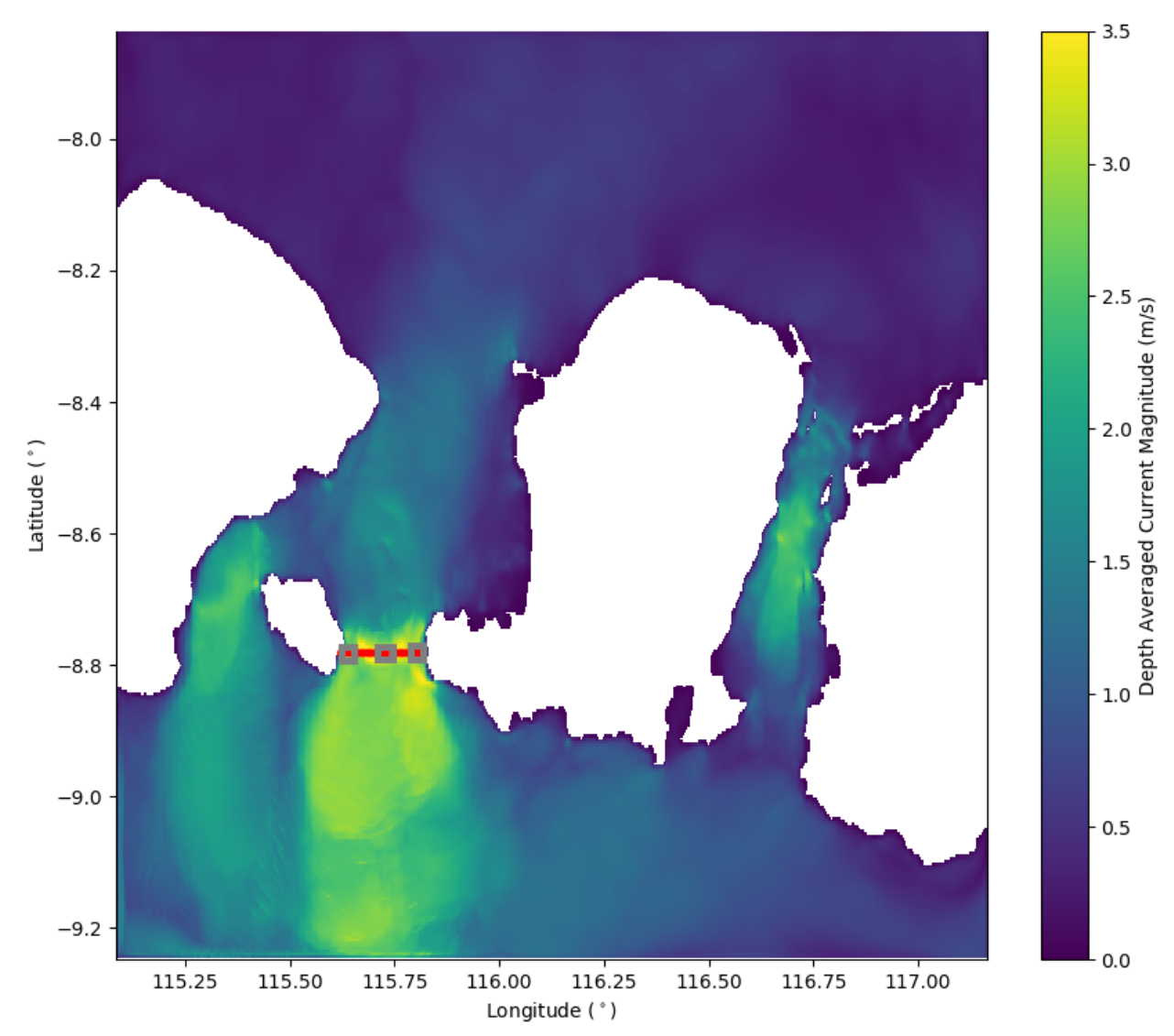

Figure 10. Maximum current velocity for tide only simulation. Red line indicates the cross sectional area extracted for the analysis and grey boxes each of the three locations analysed for Figure 12.

When the ITF is included, the situation becomes more complex. The temperature fields move from a well-mixed water column to a highly stratified layer which extends from the surface toward the 
seabed (Figure 11f), and whilst tidal streaming still occurs where the bathymetry shallows in the centre of the channel (Figure 11b), peak power densities now extend from the surface to cover the whole water column, whilst extending out eastwards, this is reflected in Figure 11d which shows the currents are accelerated towards the bottom and the edges of the channel.

Figures $11 \mathrm{~g}-\mathrm{i}$ quantify these changes, showing that the current magnitudes in the region to the east of $115^{\circ} 4^{\prime}$ E longitude are least affected by changes to the ITF.

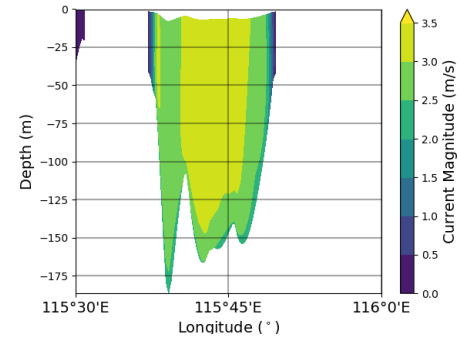

(a)

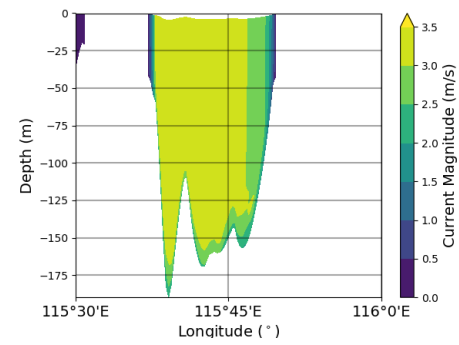

(d)

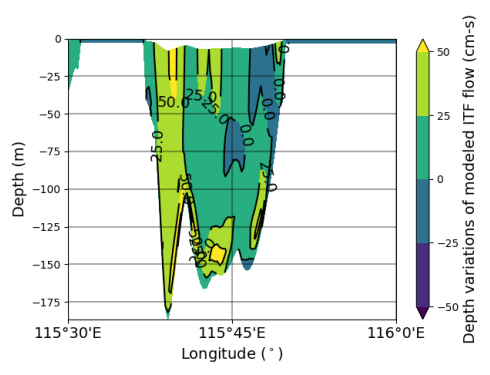

(g)

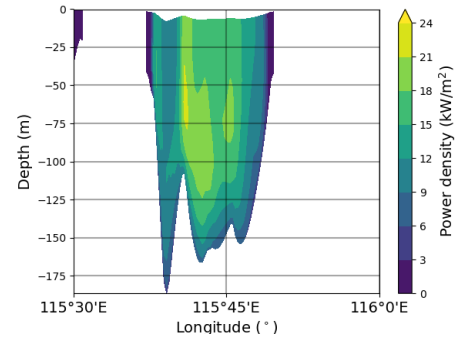

(b)

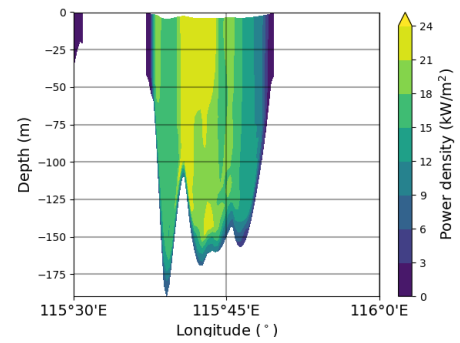

(e)

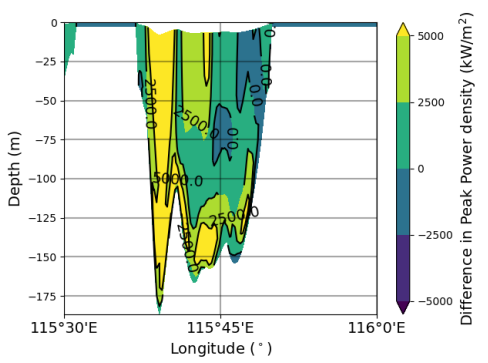

(h)

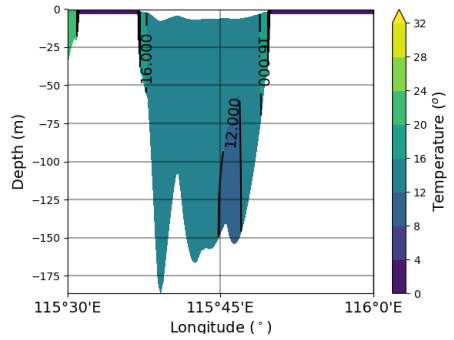

(c)

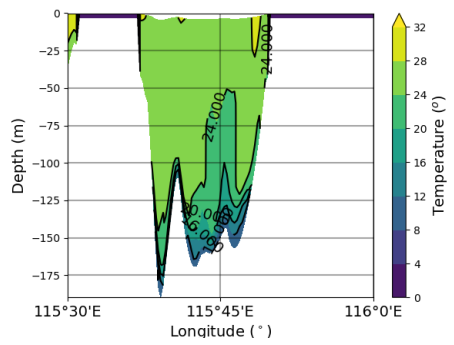

(f)

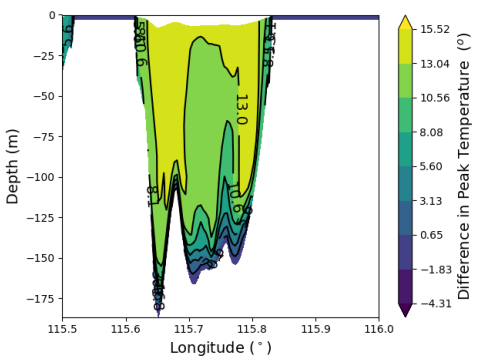

(i)

Figure 11. 3-D resource from the ROMS TO (a), and ROMS ITF simulations (d). (b,e) are the equivalent power densities $\left(\mathrm{kw} / \mathrm{m}^{2}\right)$ and temperatures $(\mathbf{c}, \mathbf{f})$ within the cross section of the Lombok strait. Difference in peak resource $(\mathbf{g})$, power $(\mathbf{h})$ and temperature (i) between tide only and ITF simulations.

By comparing the surface velocities for the weak ITF case (ITF-W; blue markers in Figure 12) with the strong ITF case (ITF-S; red markers in Figure 12), it is possible to identify how the ITF modulates the tidal flow in the channel. The ITF-W case is subtracted from the ITF-S case $(\delta U V)$ which is plotted against the signed current velocity for ITF-W and ITF-S respectively. When the velocity on the X-axis is negative it is with the direction of the ITF, when it is positive it is against the ITF direction. When $\delta U V$ is positive, it suggests that the ITF is accentuating the model velocities, when $\delta U V$ is negative the ITF is negatively effecting the tidal flow.

If we consider the ITF-W model output as our control, in accordance with the results shown in Figure 11g, the tidal velocities at the eastern side of the Lombok strait are least affected by the ITF and are only marginally accentuated when the tide is flowing in the same direction as the ITF (Figure 12c). In the centre of the transect (Figure 12b), the ITF-S velocities are predominantly negative, 
which indicates that the ITF is holding back the tide in the southward direction. The maximum velocities occur for the ITF-S case when $\delta U V$ is close to zero, due to asymmetry in the tidal flow peak tidal magnitude occurs when the tide is flowing in opposition to the ITF.

At the western most point on the transect (Figure 12a), the influence of the ITF squeezes the tide and negatively effects the peak current velocities in both north and southward directions with an overall reduction in current speed of $18 \%$ and $21 \%$ respectively. In the middle of the transect, the peak tidal speeds are enhanced by $5 \%$ in both directions and at the eastern most point on the transect, the tide is reduced by $40 \%$ when it is flowing against the ITF and increased by $40 \%$ when it is flowing with the ITF.

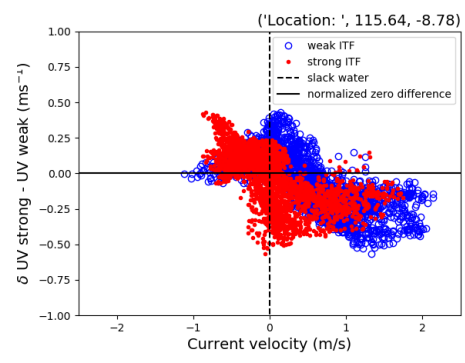

(a)

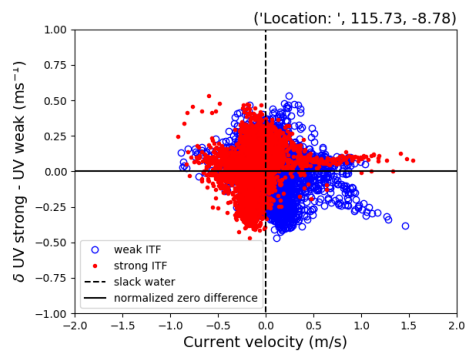

(b)

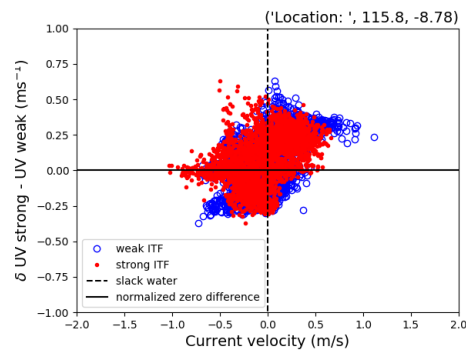

(c)

Figure 12. ITF driven variation in tidal flow at western (a), middle (b) and eastern (c) points across the Lombok Strait (see Figure 10). Blue markers indicate the tidal conditions during weak ITF conditions, red markers indicate the tidal conditions when the ITF is strong.

\section{Discussion}

Previous research into the tidal stream resource of Indonesia has predominately used 3-D Ocean Models (such as the Princeton Ocean Model, POM [4] and Delft3D [22]), forced using TPXO or OTPS tidal data sets. Using state-of-the art baroclinic modelling practices, we have shown that by improving the resolution of numerical models in this region, we are able to reduce the spatial uncertainty in the tidal resource (Figure 9). The more interesting part of the study is the impact of including the ITF. Previous studies have mentioned, but not accounted for, the variability of the ITF within resource assessments ([4,22]), and despite the well-known presence of the ITF within the Lombok Strait ([22,24]), its role in generating spatial and temporal uncertainty in tidal stream resource has been unremarked upon until now (Figures 11).

It appears from Figure 11 that the ITF is near-surface in the east, based on the assumption that the ITF transports warmer water. Certainly, the tidal currents increase when the tidal current is aligned, and moving in the direction of, the ITF. The resource to the west of the Lombok Strait shows a certain degree of asymmetry in the opposite (northward) direction to the ITF. The modulation of the resource by the ITF, results in the resource becoming more symmetrical, and to this end the southward moving ITF is somewhat of an embuggerance, inhibiting the tidal current flow in the northwards direction (Figure 12a). In the centre of the strait, where the resource was more symmetrical, when the ITF is strong there is a greater asymmetry in favour of the direction of the ITF, and on the far east of the strait, the ITF variability has negligible impact on the resource. This along with variation in the vertical distribution of the resource and influence of other oceanographic factors present in the areas, such as surface waves and non-linear internal solitary waves ([7]) are all important factors for consideration when undertaking engineering developments in the region.

Internal solitary waves impact offshore structures via the associated rapid changes in current velocity, with typical durations of several minutes. The associated current velocity profiles have very high shear through the vertical, involving complete reversals in current direction, that can also have a major impact on some structures. These internal waves are also associated with some of the strongest vertical velocities occurring in the ocean, which are also of potential impact. The generation of these internal waves should be represented to some extent by the more sophisticated baroclinic models 
considered in this paper. However, the rapid variations and strong vertical velocities will probably not be resolved. Rapidly sampled site specific measurement is usually required to quantify these features, similar to other process that can be associated with ocean turbulence. The overall magnitude of the associated currents is unlikely to dominate in the shallowest regions assessed in this study, but may dominate in some of the deeper regions shown in Figure 3.

Future work ought to investigate the interaction of surface waves with the tidal resource (see [25]); however, this study finds the likely biggest uncertainty to the resource is the availability of data for validation. Hence, methods to capture flow speeds remotely, or to obtain access to non-open source data is a priority for understanding the likely resource to the region.

\section{Conclusions}

Despite sparse data sources, a hydrodynamic model was able to reproduce the flow conditions in the Lombok Strait with a reasonable degree of accuracy. The influence of accounting for the Indonesian Through Flow variability when conducting resource assessments in the Lombok straight region was found to affect the resource. Differences between using global tidal model data and tide only model data against models run with variable, strong and weak ITF scenarios, revealed complexities of resource assessment in highly baroclinic tidal environments; hence, the need to understand the spatial and temporal variability of the resource. Whilst there is clearly an appreciable resource in the Lombok Strait, we advise that developers wishing to undertake engineering projects in this region consider the complexities of the environment which may require the application of novel engineering practices.

Author Contributions: conceptualization, A.J.G.B., M.L. and S.A.S.; methodology, A.J.G.B. and S.A.S.; validation, A.J.G.B.; formal analysis, A.J.G.B.; investigation, A.J.G.B.; resources, S.A.S. and B.I.B.; data curation, S.A.S. and B.I.B.; writing-original draft preparation, A.J.G.B.; writing-review and editing, A.J.G.B., M.L., S.A.S., B.I.B., G.J.

Funding: A.J.G.B. would like to acknowledge the support of the SEACAMS2 project, which is part-funded by the European Regional Development Fund. The study formed part of a collaborative R\&D project with Knowtra Ltd. M.L. wishes to acknowledge the support of the EPSRC METRIC project EP/R034664/1.

Acknowledgments: The model simulations were made on the Super Computing Wales system (SCW), without which the main scope of this research would not have been possible. The authors are also grateful to Mike Spencer from SBS INTL LTD for providing feedback and input to this research paper from a developers perspective.

Conflicts of Interest: Knowtra Ltd is an independent consultancy which was employed to undertake a resource assessment of the Lombok Strait. Other funders had no role in the design of the study; in the collection, analyses, or interpretation of data; in the writing of the manuscript, or in the decision to publish the results.

\section{Abbreviations}

The following abbreviations are used in this manuscript:

$\begin{array}{ll}\text { GHG } & \text { Greenhouse Gas } \\ \text { ITF } & \text { Indonesian Through Flow } \\ \text { ROMS } & \text { Regional Ocean Modeling System } \\ \text { HYCOM } & \text { HYbrid Coordinate Ocean Model } \\ \text { OTPS } & \text { Oregon State University Tidal Prediction Software } \\ \text { RMSE } & \text { Root Mean Square Error } \\ \text { FES } & \text { Finite Element Solution } \\ \text { ROMS TO } & \text { ROMS Tide Only Simulation } \\ \text { ROMS ITF } & \text { ROMS Simulation Including the Indonesian Through Flow } \\ \text { POM } & \text { Princeton Ocean Model }\end{array}$




\section{References}

1. Handayani, K.; Krozer, Y.; Filatova, T. Trade-offs between electrification and climate change mitigation: An analysis of the Java-Bali power system in Indonesia. Appl. Energy 2017, 208, 1020-1037. [CrossRef]

2. Tharakan, P. Summary of Indonesia's Energy Sector Assessment; ADB Indonesia: Metro Manila, Philippines, 2015.

3. Firdaus, A.M.; Houlsby, G.T.; Adcock, T.A. Opportunities for Tidal Stream Energy in Indonesian Waters. In Proceedings of the 12th European Wave and Tidal Energy Conference, Cork, Ireland, 27 August-1 September 2017.

4. Blunden, L.S.; Bahaj, A.S.; Aziz, N.S. Tidal current power for Indonesia? An initial resource estimation for the Alas Strait. Renew. Energy 2013, 49, 137-142.10.1016/j.renene.2012.01.046. [CrossRef]

5. Encyclopædia Britannica. Indonesia. Available online: https://www.britannica.com/place/Indonesia (accessed on 22 July 2019).

6. Wyrtki, K. Indonesian through flow and the associated pressure gradient. J. Geophys. Res. Oceans 1987, 92, 12941-12946. [CrossRef]

7. Jeans, G. Forecasting the Occurrence of Internal Solitons in Regions of Offshore Oil and Gas Activity; Oceanology International: London, UK, 2002.

8. Mitnik, L.; Alpers, W.; Lim, H. Thermal plumes and internal solitary waves generated in the Lombok Strait studied by ERS SAR. In Proceedings of the ERS-Envisat Symposium: Looking down to Earth in the New Millennium, Gothenburg, Sweden, 16-20 October 2000; pp. 16-20.

9. Kuswardani, R.T.D.; Qiao, F. Influence of the Indonesian Throughflow on the upwelling off the east coast of South Java. Chin. Sci. Bull. 2014, 59, 4516-4523. [CrossRef]

10. Fang, G.; Wang, Y.; Wei, Z.; Fang, Y.; Qiao, F.; Hu, X. Interocean circulation and heat and freshwater budgets of the South China Sea based on a numerical model. Dyn. Atmos. Oceans 2009, 47, 55-72. [CrossRef]

11. Gordon, A.L.; Fine, R.A. Pathways of water between the Pacific and Indian oceans in the Indonesian seas. Nature 1996, 379, 146. [CrossRef]

12. Robins, P.E.; Neill, S.P.; Lewis, M.J.; Ward, S.L. Characterising the spatial and temporal variability of the tidal-stream energy resource over the northwest European shelf seas. Appl. Energy 2015, 147, 510-522. [CrossRef]

13. Pawlowicz, R.; Beardsley, B.; Lentz, S. Classical tidal harmonic analysis including error estimates in MATLAB using T_TIDE. Comput. Geosci. 2002, 28, 929-937. [CrossRef]

14. Cornett, A.; Toupin, M.; Nistor, I. Appraisal of IEC technical specification for tidal energy resource assessment at Minas Passage, Bay of Fundy, Canada. In Proceedings of the 11th European Wave and Tidal Energy Conference, Nantes, France, 6-11 September 2015.

15. Neill, S.P.; Hashemi, M.R.; Lewis, M.J. The role of tidal asymmetry in characterizing the tidal energy resource of Orkney. Renew. Energy 2014, 68, 337-350. [CrossRef]

16. Warner, J.C.; Sherwood, C.R.; Signell, R.P.; Harris, C.K.; Arango, H.G. Development of a three-dimensional, regional, coupled wave, current, and sediment-transport model. Comput. Geosci. 2008, 34, 1284-1306. [CrossRef]

17. Amante, C.; Eakins, B.W. ETOPO1 Arc-Minute Global Relief Model: Procedures, Data Sources and Analysis; NOAA Technical Memorandum NESDIS NGDC-24; National Geophysical Data Center, Marine Geology and Geophysics Division: Boulder, CO, USA, March 2009.

18. Egbert, G.D.; Erofeeva, S.Y. Efficient inverse modeling of barotropic ocean tides. J. Atmos. Ocean. Technol. 2002, 19, 183-204. [CrossRef]

19. Dee, D.P.; Uppala, S.; Simmons, A.; Berrisford, P.; Poli, P.; Kobayashi, S.; Andrae, U.; Balmaseda, M.; Balsamo, G.; Bauer, P.; et al. The ERA-Interim reanalysis: Configuration and performance of the data assimilation system. Q. J. R. Meteorol. Soc. 2011, 137, 553-597. [CrossRef]

20. Metzger, E.; Hurlburt, H.; Xu, X.; Shriver, J.F.; Gordon, A.; Sprintall, J.; Susanto, R.v.; Van Aken, H. Simulated and observed circulation in the Indonesian Seas: 1/12 global HYCOM and the INSTANT observations. Dyn. Atmos. Oceans 2010, 50, 275-300. [CrossRef]

21. Susanto, R.; Mitnik, L.; Zheng, Q. Ocean internal waves observed in the Lombok Strait. Oceanography 2005, 18, 80-87. [CrossRef] 
22. Orhan, K.; Mayerle, R.; Narayanan, R.; Pandoe, W. Investigation of the Energy Potential From Tidal Stream Currents In Indonesia. Coast. Eng. Proc. 2017, 1, 10. [CrossRef]

23. Carrere, L.; Lyard, F.; Cancet, M.; Guillot, A. FES 2014, a new tidal model-Validation results and perspectives for improvements. In Proceedings of the ESA Living Planet Symposium, Prague, Czech Republic, 9-13 May 2016.

24. Ray, R.D.; Susanto, R.D. A fortnightly atmospheric 'tide'at Bali caused by oceanic tidal mixing in Lombok Strait. Geosci. Lett. 2019, 6, 6. [CrossRef]

25. Lewis, M.; Neill, S.; Hashemi, M.; Reza, M. Realistic wave conditions and their influence on quantifying the tidal stream energy resource. Appl. Energy 2014, 136, 495-508. [CrossRef]

(C) 2019 by the authors. Licensee MDPI, Basel, Switzerland. This article is an open access article distributed under the terms and conditions of the Creative Commons Attribution (CC BY) license (http:/ / creativecommons.org/licenses/by/4.0/). 